\title{
Daniel Slutzky. Estructura social agraria y agroindustrial del Nordeste de la Argentina: desde la incorporación a la economía nacional al actual subdesarrollo concentrador y excluyente. Posadas: Editorial Universitaria de la Universidad Nacional de Misiones, 2014, 572 p.
}

\author{
Pedro R. Castillo * \\ * Facultad de Ciencias Económicas, Universidad de Buenos Aires, Argentina | \\ pedro castilloo@hotmail.com
}

\section{La historia crítica del Nordeste argentino}

El abordaje de la problemática regional y social del Nordeste argentino (NEA) tiene relevancia por ser una de las regiones de menor desarrollo relativo del país, situación que se ha cristalizado en una estructura económica dual con un sector empresarial moderno de gran escala, en contraste con un grupo numeroso de pequeñas y medianas empresas con menor capacidad de acumulación. El investigador Daniel Slutzky, que en su anterior libro ya había estudiado junto a Víctor Brodersohn y Cristina Valenzuela esta problemática en relación con una provincia -Dependencia interna y desarrollo: El caso del Chaco (2007)-, amplía su análisis en esta nueva obra con una mirada integral sobre la región del NEA, a partir de los principales aspectos que hacen al proceso de acumulación capitalista en la periferia nacional. Desde una perspectiva historiográfica, la presente investigación hace especial énfasis en los procesos de ocupación territorial, el marco institucional, el desarrollo de actividades productivas, la conformación de una estructura agraria funcional a la agroindustria regional y los impactos sociales de su reestructuración tecno productiva a través del tiempo.

La primera parte del libro de Daniel Slutzky expone por provincia los procesos políticos e institucionales que 
dieron lugar a la incorporación del territorio a la economía nacional. El análisis se realiza en forma detallada para cada una de las cuatro provincias de esta región, con atención específica a sus principales producciones -destinadas a la puesta en valor de los recursos naturales en el mercado- en cada período

La segunda parte del libro complementa la anterior con el análisis de los cambios en el mapa productivo agrario, la distribución de la tierra y el detalle de las principales producciones agroindustriales vinculadas a las cadenas productivas del algodón, soja, ganado, arroz, yerba mate, té, tabaco y la foresto industria, en un período signado por grandes transformaciones tecnológicas y productivas. Se estudian también las condiciones macroeconómicas que favorecieron la incorporación de nuevas tecnologías acordes con economías de esta escala. Esas condiciones prevalecieron desde mediados de la década de 1970 y durante el período de convertibilidad que se inicia a comienzos de 1990, y darán lugar a la desregulación de la actividad económica y la eliminación de organismos públicos que llevaban a cabo funciones de intervención en los mercados, hecho que afectó a las principales actividades productivas regionales: granos, carnes, azúcar, algodón y yerba mate.

En efecto, el autor señala que durante la dictadura militar de 1976 el retroceso en la distribución del ingreso implicó menor demanda efectiva por parte de los asalariados y tuvo consecuencias sobre las producciones de bienes de consumo de la región, como el algodón y la yerba mate, así como también sobre aquella producción agraria e industrial que abastecía principalmente al mercado interno. Además, la apertura importadora de fibras para la industria impuso un quiebre dentro del complejo textil debido a que la reducción de precio del algodón en bruto benefició a las hilanderías por el abaratamiento de su materia prima.

Según Slutzky, las políticas públicas detalladas para este período influyeron en la estructura socioeconómica agropecuaria y afectaron especialmente a la pequeña producción agraria. En especial expone las medidas de política económica tomadas a partir de la década de 1990 como la sobrevaluación del peso, los aumentos significativos de los costos de producción y servicios debido a las privatizaciones, las altas tasas de interés para el financiamiento, la desregulación del comercio de granos, la liquidación de las juntas de granos, carnes, algodón y de la Comisión Reguladora de la Yerba Mate (CRYM) -que regulaba los precios a través de un mercado consignatario de yerba canchada-; también habla sobre la reforma tributaria que aumentó la presión impositiva sobre el agro, la reducción de aranceles a la importación de maquinaria e insumos agropecuarios, y la flexibilización de los plazos y condiciones de los contratos de arrendamiento, aparcerías rurales y contratos accidentales.

La investigación exhibe que, curiosamente, la única institución que superó esta tendencia general disolutiva hasta la actualidad es el Fondo Especial del Tabaco, que opera como una transferencia de ingresos del consumidor al productor, pero que tiene como efectos secundarios el financiamiento de inversiones sectoriales, subsidio a las exportaciones y la promoción de producciones alternativas. Ante el desmantelamiento de la mayor parte de las instituciones de soporte para la producción primaria regional, las posibilidades que quedaban para los pequeños productores agrarios ante la baja de rentabilidad fueron: la salida del circuito productivo, que permitía en una etapa intermedia resistir a costa de la pérdida parcial de capital; transformarse en rentista o, si contaban suficientes recursos, emprender la intensificación productiva con la incorporación de un paquete de innovaciones genéticas, mecánicas, químicas y de gestión que permitían obtener mayores rindes y seguir compitiendo con un esquema productivo diversificado.

Se destaca en el texto que durante las crisis cíclicas se manifiesta una creciente conflictividad social que reflejaba los reclamos urgentes, vinculados en algunos casos a los precios de los productos, créditos, la necesidad de establecer formas de regulación pública en la actividad económica, y la titulación de tierras en situación irregular que llevaban adelante sobre todo los productores campesinos. En el caso del reclamo de 
los yerbateros en Misiones, la respuesta fue la creación del Instituto Nacional de la Yerba Mate (INYM), que no tiene las mismas atribuciones que anteriormente tenía la CRYM al intervenir en el precio a través de la compra de yerba al productor por medio de un mercado consignatario.

Los ciclos económicos de carácter global son presentados a escala regional como ciclos de producto con distintas fases, desde la expansión hasta llegar al máximo desarrollo, posterior estancamiento y declinación de actividades productivas que dejarán su impronta en los distintos períodos en los que se subdivide el análisis histórico.

Si bien varias de estas economías regionales, particularmente algodón y yerba mate, se desarrollaron originalmente con un fuerte proceso de colonización que dio lugar a una extendida capa de pequeños y medianos propietarios, la seguridad en la tenencia de la tierra no ha sido condición suficiente de su consolidación productiva, sino que dependió directamente de la superficie original con que contaba cada unidad productiva para permitir cierto grado de acumulación en el tiempo. Como se demuestra a lo largo del libro, los pequeños y medianos productores con bajos niveles de capitalización fueron los que en mayor medida redujeron su capacidad de reproducción y subsistieron en condiciones de calidad de vida deteriorada buscando complementar sus ingresos con actividades extraprediales.

La expansión de la frontera agropecuaria, favorecida por un ciclo de precipitaciones superiores a lo normal para la región, afectó a los pequeños productores, ocupantes tradicionales de tierras fiscales y privadas, comuneros, pueblos indígenas y aparceros precarios. El corrimiento de las isohietas hacia el oeste y la posibilidad de realizar cultivos extensivos en grandes superficies desmontadas han sido los motores de la revalorización productiva y económica de las tierras, lo que da lugar a su venta o arriendo a grupos empresariales con la consecuente expulsión de sus ocupantes en situación precaria. Extensas superficies de monte ya degradado por la extracción maderera y la explotación ganadera son deforestadas para ser incorporadas a la producción agrícola en general, con predominio del cultivo de soja.

En cuanto a las economías regionales, se evidencia una sensible disminución de la fuerza de trabajo por la mecanización de las tareas de cosecha -principalmente en el algodón-, la introducción de herbicidas en el proceso agrícola y la sustitución de estas superficies por cultivos extensivos pampeanos con menores requerimientos de horas de trabajo agrario por unidad de superficie. La mayor concentración técnica de la producción en un reducido número de empresas agropecuarias y agroindustriales capital intensivas también resta dinamismo al mercado de trabajo y repercute en el deterioro de condiciones de ingreso de gran parte de la población.

Como anticipa el título del libro, el resultado de la concentración técnica y económica del NEA hace referencia a pocos ganadores. Por un lado, conglomerados de empresas que se despliegan con variado grado de integración vertical a partir de una estructura de grandes empresas diversificadas en sectores emergentes como el sojero, ganadero y arrocero, y, por último, un reducido número de empresas que dominan el núcleo transformador y comercial de los tradicionales complejos agroindustriales como la foresto industria, la elaboración de yerba mate, té y tabaco.

El proceso de desarrollo regional no es ajeno al contexto nacional, dada la relación subordinada de estas provincias al centro político y económico de Buenos Aires, que ha conformado directa e indirectamente la estructura del NEA. La aplicación de políticas nacionales de desarrollo incluye una variada gama de instrumentos entre los cuales se destaca de manera concluyente la infraestructura de comunicaciones que favorece la integración física y determina la incorporación efectiva de territorios lejanos a la actividad productiva. En este sentido, si bien se registran avances, quedan inversiones pendientes en caminos, ferrocarriles y el sistema de hidrovías Paraná Paraguay y Uruguay, cuyo potencial como eje vertical de integración física no se encuentra debidamente explotado para reducir el costo de fletes largos. 
Por último, el cuidadoso manejo de las fuentes de información estadística y la rigurosidad de la descripción realizada desde diferentes perspectivas permiten dar cuenta de la complejidad de los procesos económicos y sociales en la región, que el autor define como de subdesarrollo concentrador y excluyente. El abordaje metodológico empleado por Slutzky para el diagnóstico social del NEA no descuida la necesidad de transformar la realidad que describe, a través de lineamientos para esta acción. 